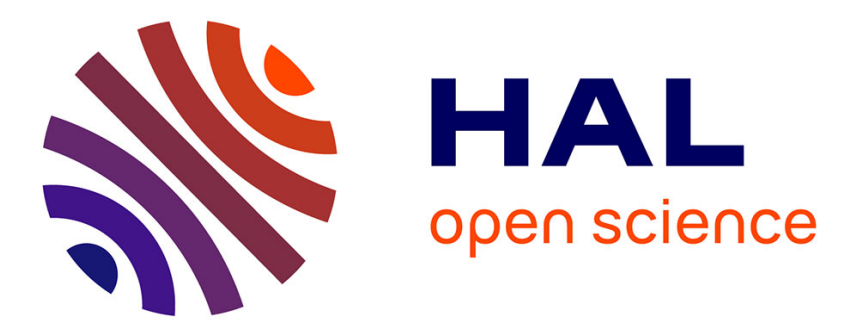

\title{
Adolescent Repeated Alcohol Intoxication as a Predictor of Young Adulthood Alcohol Abuse: The Role of Socioeconomic Context
}

\author{
Ahmed Yaogo, Eric Fombonne, France Lert, Maria Melchior
}

\section{> To cite this version:}

Ahmed Yaogo, Eric Fombonne, France Lert, Maria Melchior. Adolescent Repeated Alcohol Intoxication as a Predictor of Young Adulthood Alcohol Abuse: The Role of Socioeconomic Context. Substance Use and Misuse, 2015, pp.1-10. 10.3109/10826084.2015.1058824 . hal-01239465

\section{HAL Id: hal-01239465 https://hal.sorbonne-universite.fr/hal-01239465}

Submitted on 7 Dec 2015

HAL is a multi-disciplinary open access archive for the deposit and dissemination of scientific research documents, whether they are published or not. The documents may come from teaching and research institutions in France or abroad, or from public or private research centers.
L'archive ouverte pluridisciplinaire HAL, est destinée au dépôt et à la diffusion de documents scientifiques de niveau recherche, publiés ou non, émanant des établissements d'enseignement et de recherche français ou étrangers, des laboratoires publics ou privés. 


\section{Adolescent repeated alcohol intoxication as a predictor of young adulthood alcohol abuse:}

The role of socioeconomic context.

Ahmed Yaogo, ${ }^{1,2,3^{*}}$ Eric Fombonne, ${ }^{4}$ France Lert, $, 5,6$ Maria Melchior, ${ }^{1,2}$

\section{Author affiliations:}

${ }^{1}$ INSERM, UMR_S 1136, Pierre Louis Institute of Epidemiology and PublicHealth, Department of social epidemiology, F-75013, Paris, France.

2Sorbonne Universités, UPMC Univ Paris 06, UMR_S 1136, Pierre Louis Institute of Epidemiology and Public Health, Department of social epidemiology, F-75013, Paris, France

3University of Paris South, UMRS 1018, F-94807, Villejuif, France.

${ }^{4}$ Oregon Health \& Science University, Department of Psychiatry, Portland, Oregon, USA

5University of Versailles Saint-Quentin, UMRS 1018, F-94807, Villejuif, France.

6INSERM, U1018, Centre for Research in Epidemiology and Population Health, CESP, Epidemiology of Occupational and Social Determinants of Health, F-94807, Villejuif, France.

*Corresponding author: INSERM, U1018, Centre for Research in Epidemiology and Population Health, CESP, Epidemiology of Occupational and Social Determinants of Health, F-94807, Villejuif, France.

Hôpital Paul Brousse, 16, avenue Paul Vaillant-Couturier 94807 Villejuif, France.

E-mail: ahmed.yaogo@inserm.fr $\quad$ Phone number: +33 (0)611588677

Fax: +33 (0)177747403 
ABSRACT. Aims. Trajectories of alcohol abuse from adolescence onwards are not well known. We examined the relationship between repeated alcohol intoxication in adolescence and later alcohol abuse, testing whether this association varies depending on individuals' socioeconomic context.

Methods. Study participants ( $n=674$, age $22-35$ years in 2009) belong to the French TEMPO cohort study; their parents also participate in an epidemiological study - the GAZEL cohort. Repeated alcohol intoxication was assessed by questionnaire in adolescence (1999) (defined by $\geq 3$ episodes of alcohol intoxication in the preceding 12 months). In young adulthood (2009), alcohol abuse was assessed by the WHO AUDIT questionnaire. Socioeconomic characteristic studied was childhood family income. Data were analyzed using logistic regression models controlling for age, sex, childhood temperament, parental history of alcohol use and the quality of family relations.

Results. Among adolescents who reported repeated alcohol intoxication, 30.8\% reported alcohol abuse in young adulthood (adjusted $\mathrm{OR}=4.27,95 \% \mathrm{Cl} 2.21-8.27$ ). This association appeared stronger in participants who grew up in families with low income (adjusted $\mathrm{OR}=11.86,95 \% \mathrm{Cl} 3.35-41.94$ vs. 2.49, $95 \% \mathrm{Cl} 1.09-5.68$ for youths from families with intermediate or high income).

Conclusions. In most adolescents (69.2\%), alcohol abuse is a time-limited behavior. Nonetheless, in participants from low income families, the likelihood of persistent alcohol abuse beyond adolescence may be increased. Although some limitations are noted, a preliminary conclusion is that alcohol abuse trajectories over time need to be monitored, particularly in certain subgroups.

Keywords: Socioeconomic position; Alcohol abuse persistence; Epidemiology; Longitudinal cohort; community sample. 


\section{INTRODUCTION}

Alcohol abuse is a major public health problem worldwide (Rehm, Chisholm, Room, \& Lopez, 2006). In France, alcohol consumption has generally declined in recent years (Batel, 2011; Beck, Tovar, Spilka, Guignard, \& Richard, 2011), but levels of binge drinking and alcohol intoxication in young people may have increased (Beck, Tovar, Spilka, Guignard, \& Richard, 2011).

Alcohol abuse most frequently occurs in adolescence and tends to decrease as individuals transition to adult occupational and family roles (Kuntsche, Rehm, \& Gmel, 2004; Sanchez et al., 2011). Nonetheless, a minority of youths show patterns of alcohol abuse that persist into adulthood (Bobo, Greek, Klepinger, \& Herting, 2012; Gotham, Sher, \& Wood, 1997; Heron, Hickman, Macleod, \& Munafo, 2011; Jacob, Bucholz, Sartor, Howell, \& Wood, 2005; Jefferis, Power, \& Manor, 2005; Pitkanen, Kokko, Lyyra, \& Pulkkinen, 2008; Schulenberg \& Maggs, 2002; Widome, Wall, Laska, Eisenberg, \& NeumarkSztainer, 2013; Wu, Mao, Rockett, \& Yue, 2008). Alcohol abuse during this period of transition is especially frequent among young men (Kuntsche et al., 2004; Sanchez et al., 2011) and those who have low socioeconomic position as measured by educational attainment, employment status, or financial difficulties (Kuntsche et al., 2004). To date, evidence regarding the influence of childhood and adult socioeconomic position on alcohol use patterns among youths is mixed (Stone, Becker, Huber, \& Catalano, 2012; A. Yaogo, Fombonne, Kouanda, Lert, \& Melchior, 2013). While some prospective, community-based studies have suggested that low childhood socioeconomic position is associated with high levels of alcohol use disorders in youths, others suggest the opposite (Jackson, Sher, \& Wood, 2000; McMorris \& Uggen, 2000; A. Yaogo et al., 2013). Early alcohol abuse may indicate a vulnerability to alcohol use problems which can persist over time (Frone \& Brown, 2010), yet it is not clear whether this vulnerability varies with individuals' socioeconomic environment.

Our study specifically examines the association between repeated alcohol intoxication in adolescence and young adulthood alcohol abuse, testing whether family income in childhood modifies this relationship. Our study is based on 674 individuals who participated in the TEMPO cohort, a 
community-based study of French youths (aged 12 to 25 years in 1999 and 22 to 35 years in 2009). Our analyses control for factors that may influence the likelihood of adolescent alcohol abuse as well as long-term trajectories of alcohol use, including age, sex, childhood temperament (emotionality, impulsivity, sociability) (Dervaux, Laqueille, Bourdel, Olie, \& Krebs, 2010; Kuntsche et al., 2004; Sanchez et al., 2011), parental history of alcohol use (Kuntsche et al., 2004) and the quality of family relationships in adolescence (Dantzer, Wardle, Fuller, Pampalone, \& Steptoe, 2006; Kuntsche et al., 2004).

\section{METHODS}

\section{Study population}

The TEMPO cohort study began in 1991 among young participants whose parents participate in the GAZEL cohort study (Goldberg et al., 2007; A. Yaogo et al., 2012). They were initially surveyed in 1991 in a study on the prevalence of children's mental health problems and associated access to healthcare (Fombonne \& Vermeersch, 1997). TEMPO study participants were initially selected to be a nationally representative of French youths, particularly with regards to the socio-demographic characteristics (Melchior, Chastang, Mackinnon, Galera, \& Fombonne, 2010). The study sample was stratified by socioeconomic status and family size according to 1991 census data using the official social class codification system. The present study is based on individuals who participated in the 1999 and 2009 TEMPO study assessments ( $n=674,12$ to 25 years in 1999 and 22 to 35 years in 2009). In 1999, they were surveyed in a study on the prevalence of adolescent's mental health problems and associated access to healthcare (Fombonne \& Vermeersch, 1997). The response rate to the 1999 TEMPO mailed questionnaire was $62.2 \%(n=1,333)$. In 2009 , parents of eligible youths received a letter asking them to forward the TEMPO study questionnaire to their offspring. Of the 2,498 youths whose parents were alive and who could be contacted, 16 had died since 1991 and 4 were too ill or disabled to answer. The overall response rate to the 2009 TEMPO mailed questionnaire was $44.5 \%(n=1,103)$. This attrition may 
lead to selection bias in our study, and may reduce generalizability of our findings. However these rates are comparable with response rates of other mental health surveys in France (Alonso et al., 2004). As in many longitudinal studies, in our sample, youths from lower socioeconomic background groups were less likely to participate (Melchior et al., 2010; A. Yaogo et al., 2013). Compared to 1991 study participants, our study included a higher proportion of women $(p<0.0001)$, youths older than 16 years in $1999(p<0.0001)$, who came from non-divorced families $(p<0.0001)$ and families with intermediate/high income $(p=0.01)$. However, follow-up participants and non-participants did not significantly differ with regard to psychological characteristics and their own alcohol use in 1999. Therefore, the effect of attrition on our findings is likely to be minimal. In previous papers on this study, more detailed methodological aspects are available (Fombonne \& Vermeersch, 1997; Goldberg et al., 2007). TEMPO and GAZEL cohorts received approval from the French "Comité Consultatif sur le Traitement de l'Information en matière de Recherche dans le domaine de la Santé (CCTIRS)" and "Commission Nationale de l'Informatique et des Liberté (CNIL)", national commissions overseeing ethical data collection in France.

\section{Measures}

Alcohol abuse and other participants' characteristics were assessed in 1999 and 2009 TEMPO study questionnaires. Additionally, data on parental characteristics were available from parents' self-reports on the GAZEL study yearly questionnaire (Goldberg et al., 2007).

In young adulthood, alcohol abuse as reported by participants, was assessed in 2009 by the French version of the World Health Organization (WHO) Alcohol Use Disorder Identification Test (AUDIT) questionnaire (Redonnet, Chollet, Fombonne, Bowes, \& Melchior, 2012; Rumpf, Wohlert, Freyer-Adam, Grothues, \& Bischof, 2012). The AUDIT questionnaire is a 10-items screening test developed by the World Health Organization to match DSM IV criteria of alcohol abuse or dependence, which has been validated against clinical diagnosis (Bohn, Babor, \& Kranzler, 1995). Following published guidelines, 
participants' with an AUDIT score $>=7$ (women) or $>=8$ (men) were considered to abuse alcohol (yes vs. no).

Adolescent repeated alcohol intoxication as reported by participants, was assessed in 1999 by the following question "Have you experienced alcohol intoxication in the preceding 12 months" participants who responded yes were asked the number of times this occurred. We defined repeated alcohol intoxication as $\geq 3$ episodes of alcohol intoxication in the preceding 12 months (yes vs. no) (Beck, Tovar, Spilka, Guignard, \& Richard, 2011). Additionally, we studied regular alcohol intoxication, defined as $\geq 10$ episodes of intoxication in the preceding 12 months (yes vs. no) (Beck, Tovar, Spilka, Guignard, \& Richard, 2011)

Socioeconomic characteristic studied as potentially modifying the association between adolescent repeated alcohol intoxication and young adult alcohol abuse was family income during childhood as reported by participants' parents in 1989. In 1989, participants' parents were asked to report the range in which was their family income in Euros $(€)$ per month $(1=$ less than $762 € ; 2=[762 €-991 €[; 3=[991 €-$ $1144 €[; ; 4=[1144 €-1601 €[; 5=[1601 €-1982 €[; ; 6=[1982 €-2592 €[; 7=[2592 €-3811 €[; 8=[3811 €-$ $4574 €[$; $9=$ more than $4574 €)$. The first quartile class was $(6=[1982 €-2592 €[)$. The median class was $(7=[2592 €-3811 €[)$. Family income above the first quartile class $(6=[1982 €-2592 €[)$ was considered to be intermediate or high: (low: $<2592 €$ vs. intermediate or high: $\geq 2592 € /$ month in 1989 , which roughly corresponds to average family income in France at the time) (Bayet \& Demailly, 1996; A. Yaogo et al., 2013). Additionally, we studied family income dichotomized at the median class $(7=[2592 €-3811 €[)$. Family income above the median class was then considered to be high: (low or intermediate: $<3811 €$ vs. high: $\geq 3811 € /$ month in 1989).

Our analyses accounted for: Age [>16 vs. $\leq 16$ years in 1999; studies on a nationally representative sample of French youths reported that the average age at first alcohol intoxication was 16.1 years for males and 16.5 years for females (Com-Ruelle, Le Guen, \& Lengagne, 2013)]; Sex (Male vs. Female); Childhood temperament (Kuntsche et al., 2004) assessed retrospectively by participants' parents in 
1999 through the Emotionality Activity Sociability and Shyness (EAS) Scale (parents were asked to report on their children when they were 7-10 years of age). The EAS is a questionnaire which includes 20 items on children's temperament: emotionality (e.g. "He gets angry over nothing and cries easily"); impulsivity (e.g. "He reacts strongly when upset”); sociability (e.g. "He's very sociable")] (Gasman et al., 2002). Each item was rated on a scale from 0 to 5 and all items on each dimension of temperament are then summed. To compare participants with and without certain temperamental characteristics, we dichotomized the score at the top quartile (Yes vs. No).

Family characteristics were ascertained based on TEMPO participants' reports and their parents' reports on GAZEL study questionnaires. Parental heavy alcohol use was ascertained by TEMPO participants' reports of parental alcohol dependence, ascertained using a questionnaire adapted from the NIMH-FIGS in 2009 (Maxwell, 1992) and parents' yearly self-reported of heavy alcohol use between 1992 and 2008 [Following published guidelines, parents' with $\geq 21$ units of alcohol/week in mothers, $\geq$ 28 units of alcohol/week in fathers (Kriegbaum, Christensen, Osler, \& Lund, 2011) during the 12 preceding months were considered to present yearly heavy alcohol use]. Combining these two sources of information, we obtained a score to characterize parental heavy alcohol use during follow up period (1992-2008). Taking into account heavy alcohol use rates in general adult population in France [Studies on a nationally representative sample of French adults reported that the rates of heavy drinking varies from 7 to $14 \%$ (Beck, Tovar, Spilka, Guignard, \& J.B., 2011)], parents who were scoring above the $85^{\text {th }}$ percentile were considered to have heavy alcohol drinking during follow up period (present vs. absent). Parental divorce between 1992 to 2008 was ascertained by parental reports (yes vs. no) (Hope, Power, \& Rodgers, 1998). The quality of family relationships in adolescence was ascertained using participants' self-reports in 1999 on 4 items ("Are you satisfied with your relation with your father?"; "Are you satisfied with your relation with your mother?"; "Are you satisfied with your relation with your brother?"; "Are you satisfied with your relation with your sister?"). Each item was rated on a scale of 1-5 (from 1="very satisfied" to $5=$ "very unsatisfied"). For each item, to compare participants with and without satisfied 
family relationships, we dichotomized the score at the top quartile. Participants above the top quartile on either item were considered to have unsatisfied family relationships (Bukowski \& Sandberg, 1999) (not satisfied vs. satisfied).

\section{Statistical analysis}

Our aim was to examine the role of socioeconomic context in the association between adolescent repeated alcohol intoxication and young adulthood alcohol abuse. First, we tested unadjusted associations between adolescent repeated alcohol intoxication and young adulthood alcohol abuse. Second, we conducted multivariate regression analyses adjusted for covariates associated with alcohol use with a $p$-value $\leq 0.10$ in univariate models. We chose to retain variables significant at $p \leq 0.10$ because some variables which are not statistically associated with the study outcome at $p<0.05$ statistical significance level in univariate regression models can become statistically significant in multivariate regression models. Thus, this strategy makes it possible to include the maximum number of covariates (A. Yaogo et al., 2012). Third, the analysis was stratified by family income: 1) Socioeconomic characteristic studied as potentially modifying the association between adolescent repeated alcohol intoxication and young adult alcohol abuse was family income during childhood as reported by participants' parents in 1989; 2) The interaction term was statistically significant for family income during childhood $(p=0.006)$. We found no statistically significant interactions for $\operatorname{sex}(p=0.11)$ and for age $(p=0.92)$; therefore different age groups were studied jointly. Finally, we conducted additional analyses examining the association between regular alcohol intoxication in adolescence and alcohol abuse in young adulthood. All analyses were carried out using logistic regression models in the SAS statistical software, version 9.3 (SAS Institute Inc, North Carolina). 


\section{RESULTS}

Table1 presents participants' characteristics. $11.7 \%$ of participants reported repeated alcohol intoxication ( $\geq 3$ episodes of alcohol intoxication in the preceding 12 months) in adolescence vs. $2.3 \%$ of adolescents who reported regular alcohol intoxication ( $\geq 10$ episodes of alcohol intoxication in the preceding 12 months). $14.0 \%$ abused alcohol in young adulthood. Among participants who reported repeated alcohol intoxication in adolescence, $30.8 \%$ met criteria of alcohol abuse by young adulthood (46.7\% among participants who reported $\geq 10$ episodes of alcohol intoxication in the preceding 12 months in adolescence). In 1999, among participants who reported reported repeated alcohol intoxication, there was a higher proportion of men $(p=0.002)$, of youths older than 16 years $(p<0.0001)$, of subjects who presented parental heavy alcohol use $(p=0.1)$ and who were not satisfied with the quality of family relationships $(p<0.0001)$.

Associations between participants' characteristics and their patterns of alcohol abuse in 2009 are presented in Table 2. Adolescent repeated alcohol intoxication was associated with an increased likelihood of alcohol abuse by young adulthood (univariate $\mathrm{OR}=3.27,95 \% \mathrm{Cl} 1.90-5.63$ ).

In multivariate analyses (Table3) adjusted for age, sex, childhood temperament, parental history of alcohol use, quality of family relationships in adolescence, the OR associated with adolescent repeated alcohol intoxication increased to $4.27,95 \% \mathrm{Cl} 2.21-8.24$. Table 4 presents results of analyses examining associations between participants' adolescent repeated alcohol intoxication (in 1999) and their young adult alcohol abuse (in 2009) stratified by childhood family income. Adolescent repeated alcohol intoxication was more strongly associated with young adult alcohol abuse in youths from low income families than in those from intermediate/high income families (adjusted $\mathrm{OR}=11.86,95 \% \mathrm{Cl} 3.35-41.94$ vs. $\mathrm{OR}=2.49,95 \% \mathrm{Cl} 1.09-5.68)$ and the interaction term was statistically significant $(p=0.006)$.

In additional analyses, regular alcohol intoxication in adolescence ( $\geq 10$ episodes of alcohol intoxication in the preceding 12 months) was more strongly associated with young adult alcohol abuse than our main indicator (univariate $\mathrm{OR}=5.64,95 \% \mathrm{Cl} 1.99-15.94$ and adjusted $\mathrm{OR}=4.18,95 \% \mathrm{Cl} 1.31-13.38$ ). 
In additional analyses using childhood family income dichotomized at the median class, adolescent repeated alcohol intoxication was more strongly associated with young adult alcohol abuse in youths from low or intermediate income families than in those from high income families (adjusted OR=6.00, $95 \% \mathrm{Cl} 2.60-13.78$ vs. OR=2.34, $95 \% \mathrm{Cl} 0.72-7.67)$. This result is slightly lower but consistent with the main findings we report using childhood family income dichotomized at the first quartile class.

\section{DISCUSSION}

Main findings: Using data from a large, prospective, community-based cohort study of young adults, we found that most individuals who reported repeated alcohol intoxication in adolescence did not exhibit alcohol abuse by young adulthood. Nonetheless, adolescent repeated alcohol intoxication (defined as $\geq 3$ episodes of alcohol intoxication in the preceding 12 months) was associated with a threefold increase in the likelihood of later alcohol abuse. Participants from low-income families may be especially likely to have persistently unfavorable alcohol use pattern in case of adolescent repeated alcohol intoxication. Overall, adolescent repeated alcohol intoxication does appear to predict long-term patterns of alcohol abuse, especially certain subgroups of the population may be more likely to engage on a persistent unfavorable alcohol use pattern from a young age onwards.

\section{Adolescence repeated alcohol intoxication and young adult alcohol abuse: comparison with} prior results: In our study, $11.7 \%$ of participants reported $\geq 3$ episodes of alcohol intoxication in the preceding 12 months in adolescence and $14.0 \%$ abused alcohol in young adulthood. These rates are comparable to rates found in France in general population studies (Beck, Tovar, Spilka, Guignard, \& Richard, 2011). According to French Monitoring Centre for Drugs and Drug Addiction, in 2000, $15.8 \%$ of participants (aged 12 to 75 years old) experienced at least one episode of alcohol intoxication in the past 12 months with a peak in individuals aged from 15 to 25 years old (Guilbert et al., 2000). Consistently with prior studies, we found that most young adults who abuse alcohol did not have alcohol 
related problems in adolescence. However, adolescent repeated alcohol intoxication is associated with an increased likelihood of alcohol abuse later on in life (Chassin, Pitts, \& Prost, 2002; Dubow, Boxer, \& Huesmann, 2008; Jefferis et al., 2005; Lee et al., 2012; Windle, Mun, \& Windle, 2005). The higher the degree of alcohol abuse, the higher the likelihood of later alcohol abuse, which is also consistent with other studies (Bobo et al., 2012; Gotham et al., 1997). We also found that in emerging adulthood, among participants who didn't abuse alcohol, there was a higher proportion of women and youths from low-income families which is consistent with prior studies (Stone et al., 2012; A. Yaogo et al., 2013).

The role of childhood family income in the association between adolescent and young adult alcohol abuse: Our study main contribution is that we found that childhood family income modified the association between adolescent and young adult alcohol abuse. In case of adolescent repeated alcohol intoxication ( $\geq 3$ episodes of alcohol intoxication in the preceding 12 months), participants who grew up in families with low income were 11.86 times more likely to show persistent alcohol abuse while those who came from families with higher income were only 2.49 times more likely to show persistent alcohol abuse. This result may be explained by differences in social integration (Kuntsche et al., 2004) according to socioeconomic background. Indeed, low socioeconomic situation during childhood may have hindered study participants' academic success and their career mobility, resulting in their working in a low occupational grade. A low occupational grade may be more likely to expose to social isolation through a reduction of social functions of job (support from colleagues, exchanges) (A. Yaogo et al., 2012) and social isolation is associated with alcohol abuse (Mowbray, Quinn, \& Cranford, 2014). Our results may also be explained by differences in the perception of psychoactive substances according to socioeconomic status. Indeed, studies suggest that low socioeconomic status is correlated with underestimation of the risks of psychoactive substances abuse (de Walque, 2007; Legleye, Beck, Khlat, Peretti-Watel, \& Chau, 2012). Individuals from low income families may also be less sensitive to 
information on the health hazards of psychoactive substances abuse because their material difficulties give them a short term perspective (Legleye et al., 2012).

Strengths and limitations: Our study has limitations that need to be acknowledged before interpreting the results: 1) we had no measures of participants' alcohol use between 1999 and 2009, which limits the degree to which we can study factors that influence alcohol use in young adulthood. Future studies should consider examining the way in which youths' patterns of alcohol use evolve over time, using closer measurements; 2) Our analyses did not control for some factors known to influence young adulthood alcohol abuse because they were not available or not measured at the right time in our study [early onset of alcohol abuse (Kuntsche et al., 2004), quality of romantic relationships or family situation (Sher \& Gotham, 1999)]. Future studies should account for these factors; in addition, impulsivity was not assessed using a specific scale such as Barratt Impulsivity Scale (Patton, Stanford, \& Barratt, 1995) or a task such as the Balloon Analog Risk Task (BART)(Lejuez et al., 2002). We used Emotionality Activity Sociability and Shyness (EAS) Scale. Previous research has shown that this instrument has good psychometric properties and is generally valid against clinical diagnosis (Gasman et al., 2002). 3) Even though our study included a large community sample of youths followed prospectively from childhood to young adulthood and a prospective assessment of parental characteristics directly by parents, that is independently of youths' assessments of alcohol use, some characteristics which were self-reported may be susceptible to recall bias. Our study's main strengths are: 1) a community sample of youths followed from childhood to young adulthood, which allowed us to study alcohol abuse prospectively over time; 2) parental socioeconomic and substance use characteristics which were reported directly by parents, that is independently of youths' assessments of alcohol use, which limits information bias; 3) the ability to control for sociodemographic, psychological and family factors associated with alcohol abuse in young adulthood. 


\section{CONCLUSION}

Most adolescents who abuse alcohol do not have alcohol-related problems in young adulthood. Nonetheless, adolescent repeated alcohol intoxication is predictive of adult alcohol abuse, particularly in adolescents from low income families. As secular trends in alcohol use change over time, the ways in which long-term trajectories of alcohol abuse evolve need to be monitored. A preliminary conclusion is that trajectories of alcohol abuse over time need to be monitored, particularly in certain subgroups of the population identified through this study.

\section{Authors disclosure}

Contributors: Ahmed YAOGO, Maria MELCHIOR and France LERT designed the study and Ahmed YAOGO wrote the protocol. Ahmed YAOGO managed the literature searches and summaries of previous related work, undertook the statistical analysis and wrote the first draft of the manuscript. All authors contributed to and approved the final manuscript.

Conflict of interest: All authors declare that they have no conflict of interest to report. The authors alone are responsible for the content and writing of the paper.

Funding: This research was funded by the University of Paris South and the French Ministry of HealthIReSP (TGIR Cohortes), the French Inter-departmental Mission for the Fight against Drugs and Drug addiction (MILDT), The French Institute of Cancer (INCa). Maria Melchior is the recipient of a Young Researcher Award from the French National Research Agency (ANR).

Acknowledgements: The authors wish to thank study participants as well as their parents who helped collect data for this investigation. We are grateful to the GAZEL study team for help in implementing the TEMPO cohort, to Jean-François Chastang for help with calculating study weights, to Aude Chollet and Annie Schmaus for assistance in collecting data, and to Gulizar Elidemir for help in managing the study database. 


\section{References}

Alonso, J., Angermeyer, M. C., Bernert, S., Bruffaerts, R., Brugha, T. S., Bryson, H., . . Vollebergh, W. A. (2004). Sampling and methods of the European Study of the Epidemiology of Mental Disorders (ESEMeD) project. [Multicenter Study Research Support, Non-U.S. Gov't]. Acta Psychiatr Scand Suppl(420), 8-20. doi: 10.1111/j.1600-0047.2004.00326

Batel, P. (2011). [Changing alcohol abuse patterns]. Rev Prat, 61(10), 1364-1368.

Bayet, A., \& Demailly, D. (1996). Salaires et coûts salariaux, 45 ans d'évolution. INSEE Première, 449.

Beck, F., Tovar, M. L., Spilka, S., Guignard, R., \& J.B., R. (2011). Les niveaux d'usage des drogues en France en 2010, exploitation des données du Baromètre santé 2010. Tendances, 76.

Beck, F., Tovar, M. L., Spilka, S., Guignard, R., \& Richard, J. B. (2011). Levels of drug use in France in 2010, French office for drugs and drug addiction. Tendances, 76.

Bobo, J. K., Greek, A. A., Klepinger, D. H., \& Herting, J. R. (2012). Predicting 10-Year Alcohol Use Trajectories Among Men Age 50 Years and Older. Am J Geriatr Psychiatry. doi: 10.1097/JGP.0b013e3182423b4b

Bohn, M. J., Babor, T. F., \& Kranzler, H. R. (1995). The Alcohol Use Disorders Identification Test(AUDIT): validation of a screening instrument for use in medical settings. J Stud Alcohol., 56(4), 423-432.

Bukowski, W. M., \& Sandberg, D. (1999). Peer relationships and quality of life. [Review]. Acta Paediatr Suppl., 88(428), 108-109.

Chassin, L., Pitts, S. C., \& Prost, J. (2002). Binge drinking trajectories from adolescence to emerging adulthood in a high-risk sample: predictors and substance abuse outcomes. J Consult Clin Psychol, 70(1), 67-78.

Com-Ruelle, L., Le Guen, N., \& Lengagne, P. (2013). Les jeunes et l'alcool : évolution des comportements, facteurs de risque et éléments protecteurs. Questions d'économie de la santé, 192.

Dantzer, C., Wardle, J., Fuller, R., Pampalone, S. Z., \& Steptoe, A. (2006). International study of heavy drinking: attitudes and sociodemographic factors in university students. J Am Coll Health, 55(2), 83-89. doi: 10.3200/JACH.55.2.83-90

de Walque, D. (2007). Does education affect smoking behaviors? Evidence using the Vietnam draft as an instrument for college education. J Health Econ, 26(5), 877-895. doi: 10.1016/j.jhealeco.2006.12.005

Dervaux, A., Laqueille, X., Bourdel, M. C., Olie, J. P., \& Krebs, M. O. (2010). Impulsivity and sensation seeking in alcohol abusing patients with schizophrenia. Front Psychiatry, 1, 135. doi: 10.3389/fpsyt.2010.00135

Dubow, E. F., Boxer, P., \& Huesmann, L. R. (2008). Childhood and adolescent predictors of early and middle adulthood alcohol use and problem drinking: the Columbia County Longitudinal Study. [Research Support, N.I.H., Extramural Research Support, Non-U.S. Gov't Research Support, U.S. Gov't, Non-P.H.S.]. Addiction, 103 Suppl 1, 36-47. doi: 10.1111/j.13600443.2008.02175.x

Fombonne, E., \& Vermeersch, S. (1997). [Children of the GAZEL Cohort: I--Prevalence of contacts with the medico-educational system for psychological reasons, and associated factors]. [Research Support, Non-U.S. Gov't]. Rev Epidemiol Sante Publique, 45(1), 29-40.

Frone, M. R., \& Brown, A. L. (2010). Workplace substance-use norms as predictors of employee substance use and impairment: a survey of U.S. workers. J Stud Alcohol Drugs, 71(4), 526534.

Gasman, L., Purper-Ouakil, D., Michel, G., Mouren-Siméoni, M. C., Bouvard, M., Perez-Diaz, F., \& Jouvent, R. (2002). Cross-cultural assessment of childhood temperament. A confirmatory factor analysis of the French Emotionality Activity and Sociability (EAS)questionnaire. Eur Child Adolesc Psychiatry., 11(3), 101-107. 
Goldberg, M., Leclerc, A., Bonenfant, S., Chastang, J. F., Schmaus, A., Kaniewski, N., \& Zins, M. (2007). Cohort profile: the GAZEL Cohort Study. [Research Support, Non-U.S. Gov't]. Int J Epidemiol, 36(1), 32-39. doi: 10.1093/ije/dyl247

Gotham, H. J., Sher, K. J., \& Wood, P. K. (1997). Predicting stability and change in frequency of intoxication from the college years to beyond: individual-difference and role transition variables. J Abnorm Psychol, 106(4), 619-629.

Guilbert, P., Baudier, F., Gauthier, A., Goubert, A. C., Arwidson, P., \& Janvrin, M. P. (2000). Baromètre Santé 2000 (CFES ed. Vol. 1). Paris: Comité Français d'Education pour la Santé.

Heron, J., Hickman, M., Macleod, J., \& Munafo, M. R. (2011). Characterizing patterns of smoking initiation in adolescence: comparison of methods for dealing with missing data. Nicotine Tob Res, 13(12), 1266-1275. doi: 10.1093/ntr/ntr161

Hope, S., Power, C., \& Rodgers, B. (1998). The relationship between parental separation in childhood and problem drinking in adulthood. [Research Support, Non-U.S. Gov't]. Addiction, 93(4), 505-514.

Jackson, K. M., Sher, K. J., \& Wood, P. K. (2000). Trajectories of concurrent substance use disorders: a developmental, typological approach to comorbidity. [Research Support, U.S. Gov't, P.H.S.]. Alcohol Clin Exp Res, 24(6), 902-913.

Jacob, T., Bucholz, K. K., Sartor, C. E., Howell, D. N., \& Wood, P. K. (2005). Drinking trajectories from adolescence to the mid-forties among alcohol dependent males. J Stud Alcohol, 66(6), 745755.

Jefferis, B. J., Power, C., \& Manor, O. (2005). Adolescent drinking level and adult binge drinking in a national birth cohort. [Research Support, Non-U.S. Gov't]. Addiction, 100(4), 543-549. doi: 10.1111/j.1360-0443.2005.01034.x

Kriegbaum, M., Christensen, U., Osler, M., \& Lund, R. (2011). Excessive drinking and history of unemployment and cohabitation in Danish men born in 1953. [Research Support, Non-U.S. Gov't]. Eur J Public Health, 21(4), 444-448. doi: 10.1093/eurpub/ckq152

Kuntsche, E., Rehm, J., \& Gmel, G. (2004). Characteristics of binge drinkers in Europe. [Research Support, Non-U.S. Gov't Review]. Soc Sci Med, 59(1), 113-127. doi: 10.1016/j.socscimed.2003.10.009

Lee, J. O., Hill, K. G., Guttmannova, K., Bailey, J. A., Hartigan, L. A., Hawkins, J. D., \& Catalano, R. F. (2012). The effects of general and alcohol-specific peer factors in adolescence on trajectories of alcohol abuse disorder symptoms from 21 to 33 years. Drug Alcohol Depend, 121(3), 213219. doi: 10.1016/j.drugalcdep.2011.08.028

Legleye, S., Beck, F., Khlat, M., Peretti-Watel, P., \& Chau, N. (2012). The influence of socioeconomic status on cannabis use among French adolescents. J Adolesc Health, 50(4), 395-402. doi: 10.1016/j.jadohealth.2011.08.004

Lejuez, C. W., Read, J. P., Kahler, C. W., Richards, J. B., Ramsey, S. E., Stuart, G. L., . . Brown, R. A. (2002). Evaluation of a behavioral measure of risk taking: the Balloon Analogue Risk Task (BART). . J Exp Psychol Apll. , 8(2), 75-84.

Maxwell, M. E. (1992). Family Interview for Genetic Studies (FIGS): A Manual for FIGS. Clinical Neurogenetics Branch, Intramural Research Program, National Institute of Mental Health. Bethesda, Maryland.

McMorris, B. J., \& Uggen, C. (2000). Alcohol and employment in the transition to adulthood. [Research Support, Non-U.S. Gov't Research Support, U.S. Gov't, P.H.S.]. J Health Soc Behav, 41(3), 276-294.

Melchior, M., Chastang, J. F., Mackinnon, D., Galera, C., \& Fombonne, E. (2010). The intergenerational transmission of tobacco smoking--the role of parents' long-term smoking trajectories. [Research Support, Non-U.S. Gov't]. Drug Alcohol Depend, 107(2-3), 257-260. doi: 10.1016/j.drugalcdep.2009.10.016 
Mowbray, O., Quinn, A., \& Cranford, J. A. (2014). Social networks and alcohol use disorders: findings from a nationally representative sample. [Research Support, N.I.H., Extramural]. Am J Drug Alcohol Abuse, 40(3), 181-186. doi: 10.3109/00952990.2013.860984

Patton, J. H., Stanford, M. S., \& Barratt, E. S. (1995). Factor structure of the Barratt impulsiveness scale. J Clin Psychol. , 51(6), 768-774.

Pitkanen, T., Kokko, K., Lyyra, A. L., \& Pulkkinen, L. (2008). A developmental approach to alcohol drinking behaviour in adulthood: a follow-up study from age 8 to age 42. [Research Support, Non-U.S. Gov't]. Addiction, 103 Suppl 1, 48-68. doi: 10.1111/j.1360-0443.2008.02176.x

Redonnet, B., Chollet, A., Fombonne, E., Bowes, L., \& Melchior, M. (2012). Tobacco, alcohol, cannabis and other illegal drug use among young adults: the socioeconomic context. [Research Support, Non-U.S. Gov't]. Drug Alcohol Depend, 121(3), 231-239. doi: 10.1016/j.drugalcdep.2011.09.002

Rehm, J., Chisholm, D., Room, R., \& Lopez, A. D. (2006). Alcohol. In D. T. Jamison, J. G. Breman, A. R. Measham, G. Alleyne, M. Claeson, D. B. Evans, P. Jha, A. Mills \& P. Musgrove (Eds.), Disease Control Priorities in Developing Countries (2nd ed.). Washington (DC).

Rumpf, H. J., Wohlert, T., Freyer-Adam, J., Grothues, J., \& Bischof, G. (2012). Screening Questionnaires for Problem Drinking in Adolescents: Performance of AUDIT, AUDIT-C, CRAFFT and POSIT. Eur Addict Res, 19(3), 121-127. doi: 10.1159/000342331

Sanchez, Z. M., Martins, S. S., Opaleye, E. S., Moura, Y. G., Locatelli, D. P., \& Noto, A. R. (2011). Social factors associated to binge drinking: a cross-sectional survey among Brazilian students in private high schools. [Research Support, N.I.H., Extramural Research Support, Non-U.S. Gov't]. BMC Public Health, 11, 201. doi: 10.1186/1471-2458-11-201

Schulenberg, J. E., \& Maggs, J. L. (2002). A developmental perspective on alcohol use and heavy drinking during adolescence and the transition to young adulthood. J Stud Alcohol Supp/(14), 54-70.

Sher, K. J., \& Gotham, H. J. (1999). Pathological alcohol involvement: a developmental disorder of young adulthood. [Review]. Dev Psychopathol, 11(4), 933-956.

Stone, A. L., Becker, L. G., Huber, A. M., \& Catalano, R. F. (2012). Review of risk and protective factors of substance use and problem use in emerging adulthood. [Research Support, U.S. Gov't, P.H.S. Review]. Addict Behav, 37(7), 747-775. doi: 10.1016/j.addbeh.2012.02.014

Widome, R., Wall, M. M., Laska, M. N., Eisenberg, M. E., \& Neumark-Sztainer, D. (2013). Adolescence to young adulthood: when socioeconomic disparities in substance use emerge. Subst Use Misuse, 48(14), 1522-1529. doi: 10.3109/10826084.2013.800885

Windle, M., Mun, E. Y., \& Windle, R. C. (2005). Adolescent-to-young adulthood heavy drinking trajectories and their prospective predictors. [Research Support, N.I.H., Extramural Research Support, U.S. Gov't, P.H.S.]. J Stud Alcohol, 66(3), 313-322.

Wu, B., Mao, Z. F., Rockett, I. R., \& Yue, Y. (2008). Socioeconomic status and alcohol use among urban and rural residents in China. [Comparative Study]. Subst Use Misuse, 43(7), 952-966. doi: 10.1080/10826080701204961

Yaogo, A., Chastang, J. F., Goldberg, M., Zins, M., Younès, N., \& Melchior, M. (2012). Occupational grade and depression course in a non-clinical setting: results from the French GAZEL cohort study. [Research article]. J Depress Anxiety, 1(2), 111-117. doi: 10.4172/2167-1044.1000111

Yaogo, A., Fombonne, E., Kouanda, S., Lert, F., \& Melchior, M. (2013). Lifecourse Socioeconomic Position and Alcohol Use in Young Adulthood: Results from the French TEMPO Cohort Study. Alcohol Alcohol, 48(4), 1-8. doi: 10.1093/alcalc/agt128 